\title{
Effects of Physical Training on Social Skill Levels of Preschool Children
}

\author{
Arzu Ozyurek, Isa Ozkan, Zuhal Begde and Nadire Ferah Yavuz \\ Department of Child Development, Karabuk University, Karabuk 78050, Turkey
}

\begin{abstract}
Social skills should have been supported since the early childhood. Regular physical training and sporting events facilitate the development of motor and social competence skills of children in addition to being healthy. The aim of this study is to examine the effects of regularly performed physical trainings on the social skill levels of preschool children. This experimental study was designed by using pretests and posttests by using a relevant control group. The study group was composed of 42 children (21 boys and 21 girls in the age group of four) who were attending two different preschool institutions. Preschool Social Skills Rating Scale (PSSRS) teacher form was used in order to collect the data. The experimental group children had physical training for 14 weeks (2 days a week) under the control of researchers. Control group children had their routine education program with their teachers. Mann-Whitney U and Wilcoxon Signed Rank Tests were used in order to analyze the data. As a conclusion, it has been shown that physical training has significant and positive effects on the social skill levels of children. There was a significant difference between the gender of the experimental group children and PSSRS posttest scores in favor of girls $(P<0.01$ and $P<0.05)$ and scores of girls were significantly higher compared to all scores of boys.
\end{abstract}

Key words: Physical education, social skills, preschool period.

\section{Introduction}

It is very important to support the physical, cognitive, psychomotor, social and emotional developments of individuals from the early childhood. Social development is the process in which an individual acquires essential skills as a member of a society $[1,2]$.

Social skills are required to initiate the social relationships that are important to meet the expectations of the society, to maintain these relationships and to find solutions to the problems [3, 4]. Therefore, social skills can be used lifelong in order to increase the life quality and to reach the life goals. Social learning theory is one of the available theories in social skills acquisition [5].

According to Adler, individual's first years and first experiences are important for the social cohesion.

Corresponding author: Arzu Ozyurek, Ph.D., assoc. prof., research fields: child development and preschool education, parents attitudes, problem solving and social skills, memory, children's literature.
Freud emphasized that socialization has been the extension of the sensory linkage of the children established primarily with their parents and then; with other individuals in the neighborhood. Learning the system of community values and rules of the society is gained by the socialization process and it is named as "superego" according to the structural model of personality in the psychoanalytic theory [6]. According to Bandura, it is important for an individual to observe others and imitate these models in order to learn how to behave. Learning by observation contains processes such as paying attention, keeping in mind, forming a behavior and demonstrating the motivation [7].

Behaviors which are for the sake of positive associations with others are also known as prosocial attitudes and they are particularly important in peer relationships. Children with developed social skills are particularly preferred by peers and these types of children are more successful in their social life [8-10]. It has been stated that children who have lack of social 
skills and negative peer relationships in the beginning of the school life may have peer rejection, communication problems and academic failure in the childhood as well as in the adolescence period [11]. Therefore, the development of social skills is very crucial since the early childhood.

Primarily family relationships and then, associations with peers and teachers are important factors which affect the development of social skills. Socio-cultural values of the family, education level of parents, child-rearing attitudes and expectations of families affect the social skills of children. Children can perceive the social behaviors when they have an active co-operation with their mothers-fathers, child minders, teachers and others in the society [12-17]. The age, gender and peer relationships of the child may affect the social skills $[18,19]$.

Social skills can be learned and they can be developed by education. Preschool education has an important role in the development of the social skills of children according to their age group. Preschool institution offers children a new environment in which they can communicate with their peers and adults. Social skills education has been developed for children who have problems particularly with their peers in order to teach them how to gain social skills [20]. Development of the social skills from the preschool period facilitates children's integration into society in their further social life. Cognitive and behavioral approaches can be used in the social skills education [21].

It has been specified that social behaviors are associated with particularly cooperative games [8]. Playing game is the most important and indispensable effort for children. Game is an important phenomenon which supports all developmental areas of a child that can be encountered during the life. Children can gain basic and social skills while playing games [19, 22]. Game based activities should be prioritized in the preschool education. In various countries, movement activities are especially planned in the preschool programs and it is emphasized that these activities develop the basic movement skills, body awareness and motor and physical adequacy of children. Activities which let the children to exercise regularly are physical training activities and sports. Regular physical training and sports develop motor skills and social competency skills in addition to the enhanced healthy status $[16,23,24]$.

There are various studies performed on the effects of physical training activities on physical and motor development of children [25-34]. However, there are limited numbers of studies which emphasize the effects of physical training on social skills [35-38]. Ministry of Education supports the idea that games and movement activities should be included in the daily education process of the preschool education program. It was suggested that at least 30 minutes should be consumed for the basic movements. The duration and types of games are under the initiative of the preschool teacher [39]. Even though the importance of the movement and game activities in the preschool education programs has been shown, particularly physical training and sports were not sufficiently referred in these studies. However, game based physical training activities, which can be provided to children from the early childhood, may be an effective way of developing of both motor and social skills. Therefore, KBU-BAP-13/2-KA-063 numbered project was supported by Karabuk University Scientific Research Project Coordinator and this study was performed in order to indicate the effects of the physical training and sports on the basic motor and social skills of preschool children. In this study, a portion of findings which were obtained in the project was included and answers were searched for the question "How the preschool physical training program affect the social skill does levels of children?" as well as the following two sub problems:

(1) Is there any difference between the children who participated in the physical training program and others with respect to their social skill levels? 
(2) Is there any difference between the social skill levels of children before and after the physical training program?

\section{Methods}

This experimental study was designed by using pretests-posttests by using relevant control group.

\subsection{Participants}

The research group consists of 42 children from two different pre-school education institutes. These 4-year students belong to Pre-school of Karabuk University, Child Development Application and Research Center and they are selected as a sample group $(n=21)$. Another same size of sample has been determined randomly from other pre-school education centers that belong to Provincial National Education Directorate. The control group was composed of 10 girls and 11 boys.

\subsection{Data Collection Tools}

In this study, the Preschool Social Skills Rating Scale (PSSRS) teacher form was used in order to evaluate the social skill levels of children. This test was developed by Omeroglu et al. [40] PSSRS, which was composed of four sub dimensions such as Initial Skills (12 items), Academic Support Skills (11 items), Friendship Skills (13 items) and Emotional Management Skills (12 items), was filled by mothers, fathers and teachers who know the children. Initial skills are fundamental abilities to gain social skills and children can easily learn them. Academic Support Skills are abilities which support the academic skills of children and facilitate their adaptation to primary school period. Friendship skills are abilities which develop the positive peer interaction of children. Emotional management skills give an opportunity to children to be aware of their negative emotions such as stress, aggression which can develop against encountered situations such as prevention, dispute/conflict. These skills also teach children how to control these negative feelings and to gain positive social responses before these feelings convert to aggressive behaviors that can damage themselves as well as others. Social development skills of children are interpreted according to the percentile norms in which there are total scores of the scale and total scores obtained from its sub dimensions. In case PSSRS sub scores of four years old children are lower than $25 \%$, it means that their social skills are rather underdeveloped compared to their peers; if their scores are higher than $25 \%$ and lower than $50 \%$ (between 44-48), it shows that their development is slower compared to peers and they should be followed up; in case their scores are higher than $50 \%$ and lower than $75 \%$ (between 49-53), it indicates that development of these children are somewhat slower than peers and education opportunities should be provided to these children; and finally; in case the scores of children is higher than $75 \%$ (54 and higher), the social skills of these children are sufficient and at the expected level [40].

\subsection{Data Collection and Analysis}

Upon obtaining the official permissions, preschool teachers were asked to fill the PSSRS teachers form with a realistic and objective perspective in the beginning of the second semester. We informed them that they would again be asked to fill the same form towards the end of the semester. The 28 game based activities were prepared for the experimental group students and the comments of child development and physical education specialists were asked. These activities were listed from simple to difficult. The experimental group children had physical training for 14 weeks (2 days a week). Each application continued for approximately 30-50 minutes according to the features of the activity and the interests of children. Activities were planned in order not to prevent the daily education program. Preschool teachers also participated in these activities. Control group students continued their routine education program under the 
supervision of their teachers. In the end of the 14 weeks, the data collection tool was distributed and experimental and control group teachers were asked to fill them again.

SPSS program was used to analyze the data. In order to test the effect of physical training on the social skills of children (as mentioned in the first sub-aim of the study), Mann-Whitney U test was used due to the normally distributed data. In the second sub-aim of the study, Wilcoxon Signed Rank Test was used in order to determine that there was no difference between the results of pretest and posttest in terms of the gender of children [41]. Throughout the data analysis, it has been stated that there was no significant difference between variables when $P>$ 0.05 and there was a significant difference between variables when $P<0.05$.

\section{Limitation}

Even though children in the experimental group did not have any disadvantages with respect to the socioeconomic and cultural characteristics, there was a difference between the social skill levels pretest results of the control and experimental group. Preschool teachers who evaluated the social skills of the experimental group were different teachers and this can be considered as the limitation of the study.

\section{Results and Discussion}

In this part of the study, the PSSRS pretest and posttest mean scores of both the experimental and control groups, standard deviations, Wilcoxon Signed
Rank test results, Mann Whitney-U test results of posttest scores according to the gender of children and the interpretations of these results were given.

According to PSSRS pretest scores of the experimental group (Table 1), all of the children had lower scores than $25 \%$ in all sub dimensions and their skills were quite underdeveloped compared to their peers. According to the posttest scores of children, PSSRS Emotional Management Skills sub dimension scores were higher than $75 \%$ and their social skills were at the expected level according to their age groups. Furthermore, their total scores and scores of sub dimensions such as Initial Skills, Academic Support Skills and Friendship Skills were higher than $50 \%$ and lower than $75 \%$. Thus, their development was somewhat slower compared to their peers and these children should receive education opportunities. There was a significant difference between the PSSRS all sub dimension tests and total scores of both pretest-posttest of the experimental group $(P<0.01, P$ $<0.001)$. The posttest scores of the experimental group were shown to be significantly higher compared to their pretest scores. Thus, it can be stated that physical training activities have significant positive effects on social skills of children.

The PSSRS pretest scores of the control group (Table 2) showed that scores of children were higher than $75 \%$ in all sub dimensions of the scale and their social skills were at the normal level and sufficient compared to their peers. There was a significant difference between the pretest and posttest scores of PSSRS Initial Skills, Friendship Skills $(P<0.05)$,

Table 1 PSSRS pretest-posttest mean scores, standard deviation and Wilcoxon Signed Rank Test results of the experimental group.

\begin{tabular}{|c|c|c|c|c|c|c|c|}
\hline \multirow[t]{2}{*}{ Social Skills } & \multirow{2}{*}{$n$} & \multicolumn{2}{|c|}{$\begin{array}{c}\text { Experiment Group } \\
\text { Pre-Test } \\
\end{array}$} & \multicolumn{2}{|c|}{$\begin{array}{c}\text { Experiment Group } \\
\text { Post-Test } \\
\end{array}$} & \multirow[b]{2}{*}{$-\mathrm{Z}$} & \multirow{2}{*}{$P$} \\
\hline & & $\overline{\bar{x}}$ & Ss & $\overline{\mathrm{X}}$ & Ss & & \\
\hline Initial Skills & 21 & 39.47 & 11.19 & 52.33 & 9.59 & -3.401 & $0.001 * *$ \\
\hline Academic Support Skills & 21 & 34.80 & 10.27 & 48.28 & 7.53 & -3.671 & $0.000 * * *$ \\
\hline Friendship Skills & 21 & 37.52 & 9.55 & 56.80 & 9.89 & -3.827 & $0.000 * * *$ \\
\hline Emotional Management Skills & 21 & 24.19 & 8.35 & 49.19 & 12.81 & -3.773 & $0.000 * * *$ \\
\hline Total & 21 & 34.00 & 9.63 & 51.65 & 9.23 & -3.737 & $0.000 * * *$ \\
\hline
\end{tabular}

$* * * P<0.001, * * P<0.01$. 
Table 2 PSSRS pretest-posttest mean scores, standard deviation and Wilcoxon Signed Rank Test results of the control group.

\begin{tabular}{|c|c|c|c|c|c|c|c|}
\hline \multirow[t]{2}{*}{ Social Skills } & \multirow[b]{2}{*}{$n$} & \multicolumn{2}{|c|}{$\begin{array}{c}\text { Control Group } \\
\text { Pre-Test }\end{array}$} & \multicolumn{2}{|c|}{$\begin{array}{l}\text { Control Group } \\
\text { Post-Test }\end{array}$} & \multirow[b]{2}{*}{$\mathrm{Z}$} & \multirow[b]{2}{*}{$P$} \\
\hline & & $\overline{\bar{x}}$ & Ss & $\bar{x}$ & Ss & & \\
\hline Initial Skills & 21 & 54.47 & 9.10 & 58.47 & 5.46 & -2.207 & $0.027 *$ \\
\hline Academic Support Skills & 21 & 54.71 & 7.74 & 54.33 & 2.63 & -0.720 & 0.472 \\
\hline Friendship Skills & 21 & 59.47 & 9.60 & 63.81 & 5.45 & -2.070 & $0.038 *$ \\
\hline Emotional Management Skills & 21 & 53.57 & 8.95 & 58.76 & 5.23 & -3.074 & $0.002 * *$ \\
\hline Total & 21 & 55.55 & 8.74 & 55.55 & 8.74 & -0.225 & 0.822 \\
\hline
\end{tabular}

$* * P<0.01, * P<0.05$.

Table 3 Mann Whitney-U Test results of PSSRS posttest scores of experimental and control groups according to the gender.

\begin{tabular}{|c|c|c|c|c|c|c|c|c|c|}
\hline \multirow[b]{2}{*}{ Social Skills } & \multirow[b]{2}{*}{ Gender } & \multirow[b]{2}{*}{$n$} & \multicolumn{3}{|c|}{$\begin{array}{c}\text { Experiment Group } \\
\text { Post-Test }\end{array}$} & \multirow[b]{2}{*}{$n$} & \multicolumn{3}{|c|}{$\begin{array}{l}\text { Control Group } \\
\text { Post-Test }\end{array}$} \\
\hline & & & Mean & MWU & $P$ & & Mean & MWU & $P$ \\
\hline \multirow{2}{*}{ Initial Skills } & Female & 13 & 13.85 & \multirow{2}{*}{15.00} & \multirow{2}{*}{$0.005 * *$} & 10 & 12.10 & \multirow{2}{*}{44.00} & \multirow{2}{*}{0.259} \\
\hline & Male & 8 & 6.38 & & & 11 & 10.00 & & \\
\hline \multirow{2}{*}{$\begin{array}{l}\text { Academic Support } \\
\text { Skills }\end{array}$} & Female & 13 & 13.77 & \multirow{2}{*}{16.00} & \multirow{2}{*}{$0.005 * *$} & 10 & 12.00 & \multirow{2}{*}{45.00} & \multirow{2}{*}{0.167} \\
\hline & Male & 8 & 6.50 & & & 11 & 10.09 & & \\
\hline \multirow{2}{*}{ Friendship Skills } & Female & 13 & 13.77 & \multirow{2}{*}{16.00} & \multirow{2}{*}{$0.005 * *$} & 10 & 11.50 & \multirow{2}{*}{50.00} & \multirow{2}{*}{0.340} \\
\hline & Male & 8 & 6.50 & & & 11 & 10.55 & & \\
\hline \multirow{2}{*}{$\begin{array}{l}\text { Emotional } \\
\text { Management Skills }\end{array}$} & Female & 13 & 13.12 & \multirow{2}{*}{24.50} & \multirow{2}{*}{$0.034 *$} & 10 & 12.00 & \multirow{2}{*}{45.00} & \multirow{2}{*}{0.167} \\
\hline & Male & 8 & 7.56 & & & 11 & 10.09 & & \\
\hline \multirow{2}{*}{ Total } & Female & 13 & 13.50 & \multirow{2}{*}{19.50} & \multirow{2}{*}{$0.014^{*}$} & 10 & 12.65 & \multirow{2}{*}{38.50} & \multirow{2}{*}{0.120} \\
\hline & Male & 8 & 6.94 & & & 11 & 9.50 & & \\
\hline
\end{tabular}

$* * P<0.01, * P<0.05$.

Emotional Management Skills $(P<0.01)$ of the control group. However, there was no significant difference between academic support skills of the control group and PSSRS total posttest scores and pretest scores $(P<0.05)$. Thus, it is possible to state that the social skills of the control group showed a certain amount of increase.

As it can be seen in Table 3, there was a significant difference between the gender of the experimental group children and their PSSRS post-test and total scores $(P<0.01$ and $P<0.05)$. It was also observed that this difference was in favor of girls and the scores of girls were significantly higher than all of the scores of boys. However, there was no significant difference between the gender of the control group children and their PSSRS post-test scores $(P>0.05)$. Accordingly, social skills of the girls in the experimental group were better than the skills of boys whereas there was no significant difference between the girls and boys in the control group.

As it was mentioned before as the first sub problem in the end of the introduction part of the paper, we searched the answer of the question "Is there any difference between the children who participated in the physical training program and others regarding their social skill levels?". According to our findings, social skill levels of children, who participated in the physical training program and the ones who did not, changed in the 14 weeks time period. PSSRS posttest scores of the experimental group were significantly higher compared to their pretest scores. Yet, it has been determined that their Initial Skills, Academic Support Skills and Friendship Skills should be supported with the help of educational opportunities. PSSRS posttest scores of control group children slightly increased according to their pretest scores. Dinc [42] performed a study in which they examined the social development levels of 4-5 years old children 
who continued to preschool institutions. They showed that the social development levels increased as the age as well as the duration of the preschool education increased. Besides, teachers stated that preschool training contributed to the social development of children. Furthermore, the effects of the other factors such as mother, father and teacher attitudes on the social development of children should not be ignored. Kocak and Tepeli [43] examined the social relationships and cooperation behaviors of 4-5 years old children who were attending the preschool institution. They showed that age, gender, mother's educational status and social and economic levels influenced the cooperation and social relationships of children. According to our results, the prominent increase in the posttest scores of control group children can be due to the increasing ages well as the contribution of the preschool education to their social skills. In the study, opinions of teachers were obtained in order to evaluate the social abilities of children. Evaluation process requires being knowledgeable and experienced in this regard and the quality of teachers can affect the evaluation. Teacher should act objectively in order to make an accurate assessment. Even though researchers reminded teachers to be objective in the beginning of the study, highly developed social skills of control group children in the end of the first semester also brought to our minds the possibility of the contribution of teachers' personal feelings in the evaluation process.

As it was mentioned before, the second sub problem of the study was described with a question "Is there any difference between the social skill levels of children before and after the physical training program?". It was determined that social skills of girls in the experimental group were significantly improved compared to social skills of boys whereas there was no significant difference between the social skills of boys and girls in the control group. Social skills did not differ according to the difference in genders. Winsler and Wallace [44], Bulbul [18] and Elibol [45] stated that boys had more externalized behavior compared to girls in the preschool period. Kocak and Tepeli [43] indicated that girls had higher scores than boys in the preschool period in terms of social skills and cooperation. Kapikiran, Ivrendi and Adak [3] determined that adaptation skills of girls were less improved compared to the boys in the preschool period. In some studies, it was shown that boys and girls found solutions to problems similarly or girls produced more solutions than boys. Furthermore, it was also indicated that girls mostly used positive strategies such as sharing whereas boys mostly used negative conflict resolution strategies such as aggression [10]. In this study, all sub dimension social skill scores of girls were shown to be higher compared to the scores of boys.

In addition to these findings, it has been stated by pre-school teacher that the children, included in experiment-sample, are willing to start the day with exercises and play with materials used in activities like balance-board and water-stones. Furthermore, preschool children also mentioned that children had better motor skills and they learned the new words which were used during exercises. These findings, which were out of the aim of the study, show that physical activities and sports are also beneficial for the other developmental areas.

\section{Conclusion}

In this study, we aimed to examine the effects of physical training on social skills of preschool children, and it was determined that game based activities positively contribute to the social skills of children. It has also been found that girls had higher levels of social skills than boys. Physical training activities should be spread throughout the year and should be regularly performed in the following years because some of the social skills are slowly developed.

As a result of this study, it was seen that physical training and sports have crucial contributions in the development of both the social and motor skills of 
children. Physical training activities in the preschool period will both support the development of the children and they will also gain a lifelong sport concept in their future life. Therefore, physical training and sports should be included in the preschool programs and these activities should be regularly performed during the education year.

In this study, the social skill levels of children were assessed with the help of the perspectives of teachers. It can be recommended to perform a study in which mother, father and teacher opinions are collectively evaluated and qualitative data should be also considered apart from the quantitative data.

\section{Acknowledgements}

The authors are pleased to acknowledge the financial support for this study from Karabuk University Scientific Research Projects Department (KBU-BAP-13/2-KA-063).

\section{References}

[1] Gulay, H. and Akman, B. 2009. Social Skills in Preschool Period. Ankara: Pegem A Publishing, 16-7.

[2] Atay, M. 2011. Early Childhood Development 2. Ankara: Kök Publishing, 12-3.

[3] Kapikiran, A. N., Ivrendi, B. A. and Adak, A. 2006. "Social Skills in Preschool Children: Situation Determination." Pamukkale University Journal of Education 19 (1): 19-28.

[4] Avcioglu, H. 2009. Teaching Social Skills with Activities. (3rd ed.). Ankara: Kök Publishing, 8-10.

[5] Ozabaci, N. 2006. "A Study of the Relationship between Children' Social Skills and Those of Their Parents." Firat University Journal of Social Science 16 (1): 163-80.

[6] Gokce, F. 2013. "Analyzing the Social-Emotional Accordance of 5-6 Year-Old Children with the Parenting Attitudes of Their Mothers." Master's thesis, The Cukurova University.

[7] Senemoglu, N. 2009. Development, Learning and Teaching: Theory to Practice (14th edition), Ankara: Pegem A Publishing, 219-22.

[8] Findlay, L. C., Girardi, A. and Coplan, R. J. 2006. "Links between Empathy, Social Behavior, and Social Understanding in Early Childhood." Early Childhood Research Quarterly 21: 347-59.

[9] Rockhill, C. M., Stoep A. V., McCauley, E. and Katon, W. J. 2009. "Social Competence and Social Support as
Mediators between Comorbid Depressive and Conduct Problems and Functional Outcomes in Middle School Children." Journal of Adolescence 32 (3): 535-53.

[10] Ari, M. and Yaban, E. H. 2012. "Age and Gender Differences in Social Problem Solving Skills of 9-11 Year-Old Children." Education and Science 37 (164): 188-203.

[11] Gulay, H. 2011. "School Adjustment and Peer Relationships of 5-6 Years Old Children." Electronic Journal of Social Sciences 10 (36): 1-10.

[12] Perry Craig J., Jensen L. and Adams Gerald, R. 2001. "The Relationship between Parents Attitudes toward Child Rearing and the Sociometric Status of Their Preschool Children." The Journal of Psychology 7/9 (6): 567-74.

[13] Guralnick, M. J. 2006. "Family Influences on Early Development: Integrating the Science of Normative Development, Risk and Disability and Intervention." Handbook of Early Childhood Development, edited by McCartney and Phillips, D. Oxford, UK: Blackwell Publishers, 44-61.

[14] Berry, D. and O'conner, E. 2009. "Behavioral Risk, Teacher-Child Relationships, and Social Skill Development across Middle Childhood: A Child-By-Environment Analysis of Change." Journal of Applied Developmental Psychology (article in press).

[15] Whiteside-Mansell, L., Bradley, R. H., McKelvey, L. and Fussel, J. J. 2009. "Parenting: Linking Impacts of Interpartner Conflict to Preschool Children's Social Behavior." Journal of Pediatric Nursing 24 (5): 389-400.

[16] Kerkez, F. 2012. "Movement and Physical Activity for Healthy Growth in Preschool Aged Children." Hacettepe Journal of Sport Sciences 23 (1): 34-42.

[17] Ozyurek, A. 2015. "An Examination of the Relation Between Social Skills of Preschool Children and Mother's Child Rearing Attitudes." Journal of Education and Social Sciences 44 (206): 106-20.

[18] Bulbul, N. E. 2008. "Multi-Variable Evaluation of 4 Year Olds' Social Skills." Master's thesis. Ankara: The Ankara University.

[19] Durualp, E. and Aral, N. 2009. "Examination of the Social Cohesion and Skills of the Six Year Old Children Who Attend Kindergarden in Terms of Some Variables." Presented at the II. International Participation Child Development and Education Congress (Health, Education and Child Development) Proceedings, Ankara.

[20] Webster-Stratton, C. 1999. How to Promote Children's Social and Emotional Competence. London: Paul Chapman Publishing Ltd., 28.

[21] Bacanli, H. 2008. Social Skills Education. Ankara: Asal Publishing, 83.

[22] Kandir, A. and Tezel Sahin, F. 2011. Toys and Games 
Materials, Educational Toys in Preschool Period. Ankara: Morpa Publishing, 9.

[23] Ozyurek, A., Ozkan, I., Begde, Z. and Yavuz, N. F. 2015. "Physical Education and Sports in Preschool Period." International Journal of Science Culture and Sport (IntJSCS) Special Issue 3: 479-488.

[24] Celik, A. and Sahin, M. 2013. "Sports and Child Development." The Journal of Academic Social Science Studies JASSS-International Journal of Social Science 6 (1): 467-78.

[25] Caglak, S. 1999. "Concept (Energy) Education through Physical Education Activities for 5-6 Years Old Children Attending to Early Childhood Education Centers." Master's thesis. The Marmara University.

[26] Dursun, Z. 2004. "Effects of Physical Education Draft Program Including Basic Skills on Motor Skill Achievement of 6 Years Old Preschool Children." Master's thesis. The Hacettepe University.

[27] Kerkez, F. İ. 2004. "Effect of the Enhanced Play-Movement Program on Kindergarden Children's Locomotor Skills." Hacettepe Journal of Sport Sciences 15 (2): 76-90.

[28] Sen, M. 2004. "A Study on the Effect of Physical Education Studies on Motor Development of Size-Years Old Children Attending Kindergarten." Master's thesis, The Ankara University.

[29] Saygin, O., Polat, Y. and Karacabey, K. 2005. "The Effects of Movement Training, Applied to Children on Their Physical Fitness Parameters." Firat University Medical Journal of Health 19 (3): 205-12.

[30] Altinkok, M. 2006. "The Effects Sample Physical Education Program Aiming Motor Movement Patterns on the Development of Basic Motor Movements of Children in 5-6 Ages." Master's thesis. The Marmara University.

[31] Kirici, H. M. 2008. "The Effect of Movement Education of Eight Weeks on the Motor Performance of 4-6 Years Old Children in Preschool." Master's thesis. The Mugla University.

[32] Ozturk, A. 2009. "The Aanalysis of the Impact of the Different Movement Programme Models on the Physical Development and Developmentally Appropriate Practice of the 5-6 Years of the Age Groups." Master's thesis. The Marmara University.

[33] Cliff, D. P., Okely, A. D., Smith, L. and Mckeen, K. 2009 "Relationships between Fundamental Movement Skills and Objectively Measured Physical Activity in Pre-School Children." Pediatric Exercise Science 21 (4): 436-9.

[34] Celebi, B. 2010. "Effects of Movement Education on
Physical and Motor Developments between 5 and 6 YearOld- Children In Preschool.” Master's thesis. The Mugla University.

[35] Bayazit, B., Telci, Ş., Erenci, T. and Canerik, C. 2007. "To Analyse the Recreation Activities Effect on the Improvement of the Children's Social Growth and Confidence Feeling in the Pre-School Education Socities." Journal of Physical Education and Sport Sciences 3: 107-13.

[36] Ozkan, R. 2012. "Importance of Physical Education, Music and Art (Visual Art) Courses in Terms of Individual Development and Socialisation." E-Journal of New World Sciences Academy 7 (2). Article Number: 1c0537 Issn, 1306-3111.

[37] Orhan, B. E. 2014. "The Effects of Movement Education Upon Social Skills in Autism." Master's thesis, The Gazi University.

[38] Tsangaridou, N., Zachopoulou, E. and Liukkonen, J. 2014. "Developing Preschoolers' Social Skills through Cross-Cultural Physical Education Intervention." Early Child Development and Care 184 (11): 1550-65.

[39] MoNe. 2013. General Directorate of Primary Education, Preschool Education Programme, Ankara, 45-7.

[40] Omeroglu, E., Buyukozturk, Ş., Aydogan, Y., Cakan, M., Kilic Cakmak, E., Ozyurek, A., Gultekin, G., Gunindi, Y., Kutlu, O., Coban, A., Yurt, O., Kogar, H. and Karayol, S. 2015. "Determination ond Interpretation of the Norm Value of PreSchool Social Skills Rating Teacher Form." Educational Sciences: Theory \& Practices, EDAM 15 (4): 1-16.

[41] Buyukozturk, S. 2003. Data Analysis Manual for Social Sciences, (3rd edition) Ankara: Pegem A, 149-56.

[42] Dinc, F. D., Uluoz, E. and Sevimli, D. 2011. "Opinions on the Families about of the Children's of the Sports and Physical Activity Routing." E-Journal of New World Sciences Academy 6 (2): 93-102

[43] Kocak, N. and Tepeli, K. 2004. "Examination of the Social Skills and Cooperation Behavior in Terms of Several Variables in the 4-5 Age of Children.” Presented at the Marmara University, International Preschool Education Congress Book, Vol. II.

[44] Winsler, A. and Wallace, L. G. 2002. "Behavior Problems and Social Skills in Preschool Children: ParentTeacher Agreement and Relations with Classroom Observations." Early Education \& Development 13 (1): 41-58.

[45] Elibol, G. S. 2008. "Multi-variable Evaluation of 5 Year Olds Social Skills." Master's thesis, The Ankara University. 